\title{
Overview of Disinfection By-products and Associated Health Effects
}

\author{
Cristina M. Villanueva • Sylvaine Cordier • \\ Laia Font-Ribera $\cdot$ Lucas A. Salas • Patrick Levallois
}

Published online: 22 January 2015

(C) Springer International Publishing AG 2015

\begin{abstract}
The presence of chemical compounds formed as disinfection by-products (DBPs) is widespread in developed countries, and virtually whole populations are exposed to these chemicals through ingestion, inhalation, or dermal absorption from drinking water and swimming pools. Epidemiological evidence has shown a consistent association between long-term exposure to trihalomethanes and the risk of bladder cancer, although the causal nature of the association is not conclusive. Evidence concerning other cancer sites is insufficient or mixed. Numerous studies have evaluated reproductive implications, including sperm quality, time to pregnancy, menstrual cycle, and pregnancy outcomes such as fetal loss, fetal growth, preterm delivery, and congenital malformation. The body of evidence suggests only minor effects from high exposure during pregnancy on fetal growth indices such as small for gestational age (SGA) at birth. Populations highly exposed to swimming pools such as pool workers and professional swimmers show a higher prevalence of
\end{abstract}

This article is part of the Topical Collection on Water and Health

C. M. Villanueva $(\bowtie) \cdot$ L. Font-Ribera $\cdot$ L. A. Salas

Centre for Research in Environmental Epidemiology (CREAL),

Barcelona Biomedical Research Park (PRBB), Doctor Aiguader 88,

08003 Barcelona, Spain

e-mail: cvillanueva@creal.cat

C. M. Villanueva $\cdot$ L. Font-Ribera

IMIM (Hospital del Mar Medical Research Institute), Barcelona, Spain

C. M. Villanueva $\cdot$ L. Font-Ribera $\cdot$ L. A. Salas

CIBER Epidemiología y Salud Pública (CIBERESP), Barcelona,

Spain

C. M. Villanueva $\cdot$ L. Font-Ribera $\cdot$ L. A. Salas

Universitat Pompeu Fabra (UPF), Barcelona, Spain respiratory symptoms and asthma, respectively, although the direction of the association, and thus causality, is not clear among professional swimmers. The risk of asthma, wheezing, eczema, and other respiratory outcomes among children attending swimming pools has been the object of extensive research. Early studies suggested a positive association, while subsequent larger studies found no correlations or showed a protective association. Future research should develop methods to evaluate the effects of the DBP mixture and the interaction with personal characteristics (e.g., genetics, lifestyle), clarify the association between swimming pools and respiratory health, evaluate the occurrence of DBPs in lowand middle-income countries, and evaluate outcomes suggested by animal studies that have not been considered in epidemiological investigations.

Keywords Disinfection by-products $\cdot$ Cancer $\cdot$ Exposure $\cdot$ Reproductive $\cdot$ Respiratory $\cdot$ Swimming pools

\author{
S. Cordier \\ Inserm U1085 - IRSET, University Rennes 1, Rennes, France \\ P. Levallois \\ Direction de la santé environnementale et de la toxicologie, Institut \\ national de santé publique du, Québec, QC, Canada \\ P. Levallois \\ Département de médecine sociale et préventive, Faculté de médecine, \\ Université Laval, Québec, QC, Canada \\ P. Levallois \\ Axe Santé des populations et pratiques optimales en santé, Centre de \\ recherche du CHUQ de Québec, Québec, QC, Canada
}




\section{Introduction}

The disinfection of public drinking water supplies and swimming pool treatment is a central component of public health practices to protect the population against water-borne infections. The process of disinfection, however, leads to the formation of undesired substances. Given the widespread presence of chemicals in the form of disinfection by-products (DBPs) in treated water, virtually entire populations in developed countries are exposed, in varying degrees, to DBPs through drinking water and swimming pools. Observational studies in human populations have been ongoing since the 1970s to evaluate the health consequences of DBP exposure. Here we summarize the current evidence on DBPs with regard to occurrence, animal experimental results, potential mechanisms of action, and epidemiology, and conclude with suggestions for directions in future research.

\section{Occurrence and Regulations}

Formation of DBPs occurs as a result of the chemical reaction between organic matter in water and the disinfectant used for treatment, with more than $600 \mathrm{DBPs}$ that have been identified [1]. Chlorine is the most widespread disinfectant used worldwide, and trihalomethanes (THMs) and haloacetic acids (HAAs) are the DBP classes formed at the highest concentrations after chlorination. Other disinfectants may be used alone or in combination with chlorine. Chlorine dioxide is widely used in Italy, leading to lower levels of THMs but higher levels of chlorite and chlorate [2]. Ozone is used in combination with chlorine-based disinfectants to produce a lower volume of THMs, HAAs, and chlorine-based DBPs, but results in the production of aldehydes, ketones, keto aldehydes, carboxylic acids, keto acids, hydroxy acids, alcohols, and esters, and can also form bromate when the raw water contains bromide [3]. Disinfection with chloramines leads to the formation of nitrogenated by-products such as nitrosamines [4]. Other disinfectants may also be used, including potassium permanganate and UV radiation. Disinfectants by definition are highly reactive, however, and any one of them will lead to the formation of DBPs [5]. In addition to the effects of treatment, characteristics of raw water constitute a key determinant of DBP levels in finished drinking water or swimming pool water. The levels of precursors such as natural organic matter (e.g., humic and fulvic acids) are determinants of the DBP yield, while bromide and iodide concentrations determine the formation of brominated and iodinated DBP species $[6,7]$.

Regulations in developed countries governing disinfection by-products have established varying thresholds. The maximum contaminant level (MCL) of total trihalomethanes (the sum of chloroform, bromodichloromethane, dibromochloromethane, and bromoform) is $80 \mu \mathrm{g} / \mathrm{L}$ in the U.S. and $100 \mu \mathrm{g} / \mathrm{L}$ in the EU (although there are differences within countries in Europe). In the U.S., the MCL for haloacetic acids is $60 \mu \mathrm{g} / \mathrm{L}$ (sum of monochloro-, dichloro-, trichloro-, monobromo-, and dibromoacetic acids). Bromate is regulated in both the U.S. and EU with a limit of $10 \mu \mathrm{g} / \mathrm{L}$, and the U.S. regulatory limit for chlorate and chlorite is $700 \mu \mathrm{g} / \mathrm{L}$ for each. In addition, other DBPs are included in the World Health Organization (WHO) drinking water guidelines [8], including N-nitrosodimethylamine (NDMA), with a threshold set at $0.1 \mu \mathrm{g} / \mathrm{L}$.

\section{Experimental Evidence and Mechanisms of Action}

Several disinfection by-products have been shown to be genotoxic in in vitro assays and carcinogenic in animal experiments [1]. The WHO International Agency for Research on Cancer (IARC) has concluded that there is sufficient evidence in animals for the carcinogenicity of chloroform [9] and other widespread disinfection by-products. Experimental evidence provided by animal studies has shown fetotoxic effects, retarded fetal development, spermatotoxicity, delayed sexual maturation, changes in reproductive organs/placenta, and skeletal effects [10]. Other outcomes associated with DBP exposure in animal experiments, although less studied, are related to neurotoxicity [11-13].

Some biological mechanisms have been proposed for DBP toxicity based on experimental evidence using transgenic bacteria, mammal and human cell culture lines, and rodents [14]. Cytotoxicity, defined as an alteration in the cell integrity, with or without DNA damage, has been related to chloroform and trichloroacetic acid (TCAA). Phosgene and dichloromethyl are intermediate products of chloroform after in vivo metabolism through cytochrome P450 2E1 (CYP2E1) [15]. Phosgene is highly reactive and binds to proteins, phospholipids, and reduced glutathione cell content [16]. In human populations, exposure to DBPs in the presence of some polymorphisms of CYP2E1 has been related to an increased risk of bladder cancer [17]. The mechanism of TCAA is different, either excreted unchanged due to polar binding to plasma proteins or following a free radical-generating reductive dechlorination pathway into dichloroacetic acid which is a more potent lipoperoxidative compound [18]. In addition, other compounds may act as precursors of TCAA (chloral hydrate or trichloroethanol) [19]. Studies have reported that metabolism of brominated trihalomethanes through glutathione Stransferases such as glutathione S-transferase theta-1 (GSTT1) generates intermediate carbonyl-reactive molecules targeting the DNA in in vitro models [20-22]. Similarly, GSTT1 expression is necessary to observe genotoxicity in human cell cultures $[23,24]$. In epidemiological studies of human populations, polymorphisms in GSTT1 have been 
shown to modify the risk associated with DBP exposure, with GSTT1-positive subjects showing higher susceptibility [17]. Other molecular mechanisms such as epigenetic changes have also been observed. Global hypomethylation of DNA and hypomethylation of several proto-oncogenes after exposure to THM and HAA have been described in rodents [25-28]. There is limited human evidence of DNA methylation changes in retrotransposons or other areas of DNA [29]. Lastly, folate metabolism appears to play a role in colorectal carcinogenesis, with folate deficiency associated with increased formation of preneoplastic lesions in rodents exposed to DBPs $[30,31]$.

Mechanistic research is still limited, and further studies are needed. The complex nature of the DBP mixture hampers the evaluation of mechanisms and the attribution of their effects to specific chemicals. Global indicators of toxicity (cytotoxicity, genotoxicity, etc.), combined with chemical analysis of disinfection by-products, have recently been used to address the complex nature of DBP mixtures [32,33]. However, observational studies in humans still lack methods to address these complexities, and there have been few attempts that have demonstrated a clear improvement over traditional evaluations [34].

\section{Exposure Assessment in Human Epidemiological Studies}

The inherent complexity of DBP mixtures represents a challenge in the assessment of human exposure, which has generally been addressed by the use of specific substances as markers of the global mixture. Trihalomethanes have been used in epidemiological studies as surrogates of total DBP content, although correlations among specific DBPs are variable [35]. Given that THMs (as well as other DBPs) are volatile and skin permeable, the exposure pathways are numerous, and include ingestion of water, inhalation and skin absorption while showering, bathing, swimming in treated pools, and hand dish-washing [36]. Pharmacokinetics differs among exposure routes [37]. Experimental studies in volunteers have shown a larger internal dose and longer duration in the bloodstream from activities involving inhalation and dermal absorption compared to ingestion [36, 37]. As such, a proper exposure assessment should include ingestion and noningestion activities involving water contact in order to ascertain the relevant exposure window (Table 1).

The use of biomarkers of exposure is hampered by the short half-life of disinfection by-products in the body. Levels in exhaled air are useful in evaluating short-term exposure [41], and levels in the blood have been used in evaluations at the population level $[42,43]$. However, these biomarkers are of limited use for evaluating risks associated with cancer, reproductive outcomes, and other health effects that require longer exposure periods. Urine trichloroacetic acid has been
Table 1 Suggested periods of vulnerability for different outcomes associated with disinfection-by-product exposure

\begin{tabular}{|c|c|c|}
\hline & Vulnerable period & References/comments \\
\hline \multicolumn{3}{|l|}{ Reproductive outcomes } \\
\hline $\begin{array}{l}\text { Intrauterine } \\
\text { growth-related }\end{array}$ & $\begin{array}{c}2 \mathrm{nd} / 3 \text { rd trimesters } \\
\text { of gestation }\end{array}$ & $\begin{array}{l}\text { Lewis et al. [38]; Wright } \\
\text { et al. [39] }\end{array}$ \\
\hline $\begin{array}{l}\text { Congenital } \\
\text { anomalies }\end{array}$ & $\begin{array}{l}\text { 1st trimester } \\
\text { of gestation }\end{array}$ & Organogenesis period \\
\hline Sperm quality & 3 months & Spermatogenesis period \\
\hline Cancer (bladder) & Decades ( $>25$ years $)$ & Villanueva et al. [40] \\
\hline $\begin{array}{l}\text { Respiratory outcomes } \\
\text { (swimming pools) }\end{array}$ & $\begin{array}{l}<2 \text { years of age? } \\
\text { Childhood? }\end{array}$ & Not established \\
\hline
\end{tabular}

proposed as a valid biomarker of ingested DBPs, as its halflife is longer than consecutive exposure events, reaching steady levels that correlate with levels ingested through drinking water [44]. However, the validity of this method is limited, given that trichloroacetic acid is a metabolite of other substances, and only the ingestion pathway is covered (haloacetic acids are not volatile or skin-permeable) [45].

\section{Disinfection by-Products and Cancer}

Several epidemiological studies have been conducted to evaluate cancer risk following the discovery of chloroform in drinking water [46] and the carcinogenicity of chloroform in rodents [47]. Ecological studies showed positive correlations between mortality rates and areas with high levels of DBPs in drinking water, and were followed with case-control studies [48]. Because of methodological drawbacks (e.g., the use of certificate data, exposure assessment limitations, lack of control for confounding), better-designed studies have since been conducted. The following section summarizes the current evidence based on recent reviews.

\section{Bladder Cancer}

The bladder has been the most frequently evaluated cancer site, including two meta-analyses $[49,50]$ and two pooled analyses [40, 51•]. King (2001) analyzed six casecontrol and one cohort study, including incident cases, ascertainment of residential histories, water exposure, and confounders. The overall relative risk (RR) estimate for the highest exposure category, without specifying concentrations, was 1.5 (95\% CI, 1.3-1.8). Inconsistencies among studies were highlighted, particularly with regard to sex and smoking status. A meta-analysis by Villanueva et al. (2003) of six case-control and two cohort studies showed a combined relative risk of $1.6(95 \% \mathrm{CI}, 1.2-2.2)$ in men and 1.4 (95\% CI 0.6-3.6) in women for more than 40 years of exposure to chlorinated water. An 
exposure duration-response pattern was noted, although it did not consider the concentrations of contaminants in drinking water. Villanueva et al. (2004) conducted a pooled analysis of six case-control studies with individual-based exposure assessment of total trihalomethanes (TTHMs) in a 40-year exposure window (from 5 to 45 years before diagnosis/interview). A relationship was found only for men, with a monotonic increase in exposure-response and a pooled odds ratio (OR) of 1.4 (95\% CI, 1.2-1.7) for TTHM levels greater than $50 \mu \mathrm{g} / \mathrm{L}$. This study also reported a pooled OR of 1.6 (95 \% CI 1.22.2) among men with the longest exposure to chlorinated water (between 30 and 40 years). An updated meta- and pooled analysis by Costet et al, (2011) showed that the risk of bladder cancer in men for TTHM exposure above $50 \mu \mathrm{g} / \mathrm{L}$ was comparable between studies conducted in Europe and North America.

Overall, results from different studies and among different countries have shown fairly consistent results. Some concerns still remain, however, calling into question the robustness of this relationship [49, 52, 53]. These include the unexplained selective positive association for men, in the absence of conclusive biological explanations [40]; the inconsistencies by smoking status, since several studies found stronger relationships for smokers while others found the opposite; the absence of a plausible agent among the known DBPs capable of explaining such increased risk at the low levels of exposure observed [53]; and issues regarding the comparability of exposed and unexposed subjects. On the other hand, the consistency in epidemiological findings and the observed doseresponse relationship, at least for men, cannot be dismissed. Gene-environment interaction studies have provided some support for mechanisms of DBPs in humans. In particular, the results of a study by Cantor et al. (2010) indicated an increased risk of bladder cancer in participants with certain polymorphisms of genes coding for enzymes involved in the metabolism of DBPs [17] and of other xenobiotics [54].

\section{Colon and Rectal Cancer}

Evidence with respect to the association between DBP exposure and these cancer sites is mixed. An analysis by King et al. (2001) of four case-control studies involving incident colon cancer cases found high heterogeneity among studies (two positive and two negative) that hampered the estimation of combined relative risk [49]. Rahman et al. (2010) integrated three additional case-control studies with poorer designs, did not reject heterogeneity, and were able to estimate a combined RR for highest exposure of 1.3 (95\% CI, 1.1-1.6) [55]. For rectal cancer, the heterogeneity of results and poor quality of several studies have limited the ability to draw conclusions from any systematic reviews $[49,55]$.
Other Cancer Sites

There have been sporadic studies of other cancer sites (pancreas, kidney, brain, breast, esophagus, and lung cancer, in addition to leukemia, melanoma and non-melanoma skin cancer) [56], and the overall evidence is insufficient to determine whether an association exists.

In summary, despite almost 40 years of research, the carcinogenicity of DBPs in human populations has yet to be determined, and study continues. The available body of evidence has identified some sites, particularly the bladder, as potential targets, but lingering issues prevent definitive conclusions of causality. In particular, there is a need to understand which DBPs are the putative agents and molecular mechanisms in humans. Relationships with sex and smoking must also be clarified, as well as genetic susceptibility.

\section{Disinfection by-Products and Reproductive Outcomes}

Many reproductive studies on DBPs have been built on existing studies or existing records (birth certificates, for instance), and have relied on routine drinking water monitoring to build an exposure index at the relevant residence. Recent studies have incorporated individual information on drinking, showering, and bathing habits as various circumstances of exposure, or have used biomarkers such as measures of urinary trichloroacetic acid (TCAA). These investigations have focused on fertility effects, fetal loss, fetal growth and gestational duration, and congenital malformations.

\section{Fertility}

The potential impact of DBPs on male fertility has garnered much less attention than the effect on pregnancy outcomes, although it has some relevance based on animal evidence [57]. Epidemiological studies have generally been small and based on various population groups, such as partners in subfertile couples or, less often, presumed fertile men. Studies have suggested a negative impact of DBP exposure on normal sperm morphology [58] and on sperm concentration [59], but not on motility percentage, after adjusting for confounders [60]. A large case-control study conducted in the UK reported no evidence of poor semen quality in association with total trihalomethanes (THMs), chloroform, or brominated THMs in public drinking water [61]. In China, a cross-sectional study that measured urine TCAA in approximately 2,000 men visiting a reproduction center showed a negative correlation between markers of sperm quality and urine TCAA levels, but no dose-response association was observed [62]. Menstrual parameters as measured by urinary steroid metabolites over a period of six months were collected among a group of 
403 women, together with water use habits and THM levels at the residence. A monotonic decrease in cycle length and follicular phase length was observed in association with total THM, which was stronger with brominated compounds [63]. MacLehose et al. reported a decrease in fecundability (time to pregnancy) among women in the U.S. at sites with high levels of ingested THMs [64].

\section{Fetal Loss}

A prospective study conducted in California suggested an increased risk of spontaneous abortion among women who consumed five or more glasses of cold tap water per day containing $\geq 75 \mu \mathrm{g} /$ liter of total THMs, with a higher risk when bromodichloromethane was considered [65]. A subsequent study conducted in North Carolina with a refined exposure characterization did not confirm these results [66]. The risk of stillbirth was recently evaluated in a meta-analysis of five studies, showing an overall increase of $9 \%(2-17 \%)$ for cases with high THM exposure [67].

\section{Fetal Growth}

A large number of studies on fetal growth were published prior to 2000, and the evidence has been summarized in several review articles $[68,69]$. While many studies pointed towards an association with low birth weight, the evidence was considered inconclusive. Since then, a number of studies using careful individual exposure assessment have been conducted in areas with significant exposure to THMs [70-72, 73•, 74•]. Overall, there was no observed increase in the risk of small-for-gestational-age (SGA) neonates. Exceptions, however, were noted in areas with high concentrations of THMs $(\geq 80 \mu \mathrm{g} / \mathrm{L})$ in tap water $[71,73 \cdot]$, in cases with high uptake via showering [74•], and in susceptible populations, such as newborns carrying a genetic variant of the CYP2E1 gene [70]. The overall picture as summarized in a 2009 metaanalysis of eight studies depicted a slight increase in SGA risk with exposure to THMs [75]. Two recent studies using urinary TCAA as a biomarker of exposure suggested an impact on fetal growth in the highest exposure category $[74 \cdot, 76]$.

\section{Gestational Duration}

Studies have consistently reported no association between maternal DBP exposure and preterm delivery [75].

\section{Congenital Malformations}

Meta-analyses of available studies $(n=15)$ on the relationship between DBP exposure and various birth defects have reflected an overall $17 \%$ increase (334\%) in all congenital anomalies and, more specifically, an increased risk of ventricular septal defect, based on five and three studies, respectively. However, results relative to the category "all congenital anomalies" combined were not considered relevant by the authors, given the heterogeneity of phenotype and probable etiology when considering all anomalies together. The excess risk of ventricular septal defects was based on only three studies, and only one showed evidence of a monotonic exposure-response relationship. In addition, ventricular septal defects are among the anomalies most subject to variable diagnosis and reporting in routine anomaly registries [77]. No association with hypospadias was found in this meta-analysis (four studies). A recent investigation based on the U.S. National Birth Defects Prevention Study suggested a few increased risks (gastroschisis) associated with shower length [78]. It is worth noting that in countries where chlorine dioxide is the main water disinfectant in use, an increase in the risk of urinary tract birth defects have been observed in association with chlorite or chlorate levels in drinking water [79].

In summary, despite a large body of research, there is no clear evidence linking exposure to DBPs and reproductive outcomes, with the exception of a slight association with fetal growth-related outcomes and sporadic associations with some categories of congenital anomalies. This may be explained in part by the inherent difficulties in adequately assessing exposure levels in epidemiological studies or in comparing results from areas where water disinfection has generated hundreds of chemicals in varying proportions, where only a very small number of these interrelated pollutants are commonly assessed. Another explanation may be the absence of an effect that would be supported by the largely negative findings from experimental investigation of reproductive toxicity in rats following exposure to a "whole mixture" of DBPs representative of U.S. chlorinated drinking water [80], where previous experiments essentially focused on single DBPs or chemical classes of DBPs.

\section{Swimming Pools and Respiratory Health}

Chlorine is the most common disinfectant in use in swimming pools worldwide. It reacts with organic matter from swimmers, leading to the formation of DBPs such as nitrosamines [81] or chloramines, apart from trihalomethanes, haloacetic acids, and other DBPs that are also found in drinking water. Swimmers are exposed to these DBPs primarily through dermal absorption of skin-permeable DBPs and through inhalation of volatile DBPs. Trichloramine, a volatile compound producing a penetrating odor and causing skin irritation [82], is present in the air of indoor swimming pools. Whether exposure to this irritant environmental could 
affect the respiratory health of pool attendants is a topic of research.

\section{Occupational Exposure}

Swimming pool workers and elite swimmers are highly exposed to this environment. Three cases of occupational asthma as a result of trichloramine sensitization have been described among lifeguards [83]. Epidemiological studies have described a higher prevalence of certain respiratory symptoms among pool workers, but have reported no chronic effects [84]. Due to the cross-sectional design of these studies, however, a healthy worker effect cannot be ruled out. Several studies have shown a higher prevalence of asthma among swimmers compared to other athletes [85], but the direction of the association is not clear, given that swimming is a recommended sport for asthmatics $[85,86]$.

\section{Children}

Babies and children have a much lower exposure to swimming pools, but are particularly vulnerable. Furthermore, they attend smaller, hotter, and eventually more polluted swimming pools than adults. Studies conducted in Belgium reported an increased risk of asthma among children with atopy that was associated with early indoor [87-89] and outdoor [90] swimming pool attendance. However, studies in other European countries such as Germany [91], Spain [92, 93], the UK [94•], and the Netherlands [95], have found no association between swimming pool attendance and respiratory symptoms among children. Studies showing null associations were population-based and had larger sample sizes [91-93, 94•, 95]. The only prospective longitudinal study was performed among 5,738 British child swimmers, which found no increased risk of asthma or any respiratory or allergy symptoms at around 10 years of age [94•]. Indeed, swimming was associated with increased lung function and a lower prevalence of asthma symptoms, especially among children with pre-existing respiratory conditions [94•]. A Dutch study in which a semi-quantitative exposure assessment was performed also found no correlation between asthma or respiratory symptoms and average trichloramine levels in swimming pools [95]. Reported levels of trichloramine in swimming pool air from studies in Belgium [88, 89], Spain [92], and the Netherlands [95] have noted overall levels that were below the $0.5 \mathrm{mg} / \mathrm{m}^{3}$ recommended by the WHO [96].

In summary, a higher prevalence of respiratory symptoms, including asthma, has been found among subjects occupationally exposed to swimming pools, although the causality of this association is uncertain. Studies in children have reported contradictory results. Although further research is still needed, the available evidence suggests that, in general, the health benefits of swimming during childhood outweigh the potential respiratory health risks of chemical contamination [97].

\section{Future Directions}

Extensive research has been conducted since the first epidemiological studies in the 1970s [98] and has contributed to the current body of knowledge. Among the remaining issues concerning the epidemiology of disinfection by-products that we highlight is the complex nature of the mixture. Although DBPs occur in mixtures, only a few DBP markers have been used in epidemiological studies and do not necessarily correlate with the putative agent or the total DBP content. The evaluation of mixtures is complex, and methods are needed to tackle the exposure in a holistic manner. Animal experiments have suggested biological endpoints of DBP exposure such as neurodevelopmental outcomes and delayed puberty [11, 99], and these have not yet been evaluated in human epidemiological studies. In the few cases where the evidence is sufficiently consistent (e.g., bladder cancer), there is still room for improvement in our understanding of the biological interaction with genetics and lifestyle. Elucidation of the mechanism of action is necessary in order to provide biological plausibility and support causal associations. Mechanistic research is underdeveloped, as laboratory models may not necessarily contribute to an understanding of acute or chronic effects in humans, who are generally exposed at very low doses. Refined exposure biomarkers must be developed in future longitudinal biobanks or cohort studies. There is also a need to evaluate occurrence levels in low- and middle-income countries, where evidence is scarce. More robust studies are needed to determine whether exposure to DBPs in swimming pools during infancy and childhood can affect the risk of asthma and other respiratory, atopic, or dermal symptoms.

\section{Conclusions}

Disinfection is a critical process for the prevention of waterborne infections, and chlorination was one of the major interventions of the nineteenth century effecting a reduction in mortality. Disinfection by-products are undesired consequences of disinfection, and current technologies in developed countries allow water treatment that minimizes the formation of DBPs while maintaining microbial safety. DBPs constitute complex mixtures that may be incorporated through multiple routes (ingestion, inhalation, skin absorption), and exposure assessment is a key challenge in epidemiological studies, particularly for long-latency diseases such as cancer. Trihalomethanes have been traditionally used as markers of DBP mixtures, and long-term exposure to high levels has been 
consistently associated with an increased risk of bladder cancer among men. The evidence implicating DBP exposure during pregnancy does not show a consistent association with pregnancy outcomes, with the exception of a slight correlation with fetal growth-related outcomes. Other reproductive effects such as semen quality do not show a clear association with DBP exposure. A higher prevalence of respiratory symptoms has been described in swimming pool workers, and higher rates of asthma are found among professional swimmers. There is mixed evidence linking swimming pool attendance and respiratory health among children, although an increasing number of studies suggest that the benefits of swimming in pools outweigh the risks associated with DBP exposure.

\section{Compliance with Ethics Guidelines}

Conflict of Interest Cristina M. Villanueva, Sylvaine Cordier, Laia Font-Ribera, Lucas A. Salas, and Patrick Levallois declare that they have no conflict of interest.

Human and Animal Rights and Informed Consent This article does not contain any studies with human or animal subjects performed by any of the authors.

\section{References}

Papers of particular interest, published recently, have been highlighted as:

- Of importance

1. Richardson SD, Plewa MJ, Wagner ED, et al. Occurrence, genotoxicity, and carcinogenicity of regulated and emerging disinfection by-products in drinking water: a review and roadmap for research. Mutat Res. 2007;636(1-3):178-242.

2. Fantuzzi G, Aggazzotti G, Righi E, et al. Exposure to organic halogen compounds in drinking water of 9 Italian regions: exposure to chlorites, chlorates, trihalomethanes, trichloroethylene and tetrachloroethylene. Ann Ig. 2007;19(4):345-54.

3. von Gunten U. Ozonation of drinking water: part II. Disinfection and by-product formation in presence of bromide, iodide or chlorine. Water Res. 2003;37(7):1469-87.

4. Kristiana I, Tan J, Joll CA, et al. Formation of N-nitrosamines from chlorination and chloramination of molecular weight fractions of natural organic matter. Water Res. 2013;47(2):535-46.

5. Hua G, Reckhow DA. Comparison of disinfection byproduct formation from chlorine and alternative disinfectants. Water Res. 2007;41(8):1667-78.

6. Kampioti AA, Stephanou EG. The impact of bromide on the formation of neutral and acidic disinfection by-products (DBPs) in Mediterranean chlorinated drinking water. Water Res. 2002;36(10):2596-606.

7. Richardson SD, Fasano F, Ellington JJ, et al. Occurrence and mammalian cell toxicity of iodinated disinfection byproducts in drinking water. Environ Sci Technol. 2008;42(22):8330-8.

8. WHO. Guidelines for Drinking-water Quality. Fourth Edition. http://whqlibdoc.who.int/publications/2011/9789241548151_eng. pdf (last accessed 1st September 2014): 2011.
9. IARC. International Agency for Research on Cancer Monographs on the evaluation of carcinogenic risks to humans. Some chemicals that cause tumors of the kidney or urinary bladder in rodents and some other substances. Vol 73. In: International Agency for Research on Cancer, editor. Some chemicals that cause tumors of the kidney or urinary bladder in rodents and some other substances. Vol 73. Lyon: IARC, 1999: 131-182.

10. Tardiff RG, Carson ML, Ginevan ME. Updated weight of evidence for an association between adverse reproductive and developmental effects and exposure to disinfection by-products. Regul Toxicol Pharmacol. 2006;45(2):185-205.

11. Guariglia SR, Jenkins Jr EC, Chadman KK, et al. Chlorination byproducts induce gender specific autistic-like behaviors in CD-1 mice. Neurotoxicology. 2011;32(5):545-53.

12. Moser VC, Phillips PM, McDaniel KL, et al. Behavioral evaluation of the neurotoxicity produced by dichloroacetic acid in rats. Neurotoxicol Teratol. 1999;21(6):719-31.

13. Moser VC, Phillips PM, Levine AB, et al. Neurotoxicity produced by dibromoacetic acid in drinking water of rats. Toxicol Sci. 2004;79(1):112-22.

14. Nieuwenhuijsen MJ, Grellier J, Smith R, et al. The epidemiology and possible mechanisms of disinfection by-products in drinking water. Philos Trans A Math Phys Eng Sci. 2009;367(1904):404376.

15. Testai E, de Curtis V, Gemma S, et al. The role of different cytochrome $\mathrm{P} 450$ isoforms in in vitro chloroform metabolism. J Biochem Toxicol. 1996;11(6):305-12.

16. Gemma S, Vittozzi L, Testai E. Metabolism of chloroform in the human liver and identification of the competent P450s. Drug Metab Dispos. 2003;31(3):266-74.

17. Cantor KP, Villanueva CM, Silverman DT, et al. Polymorphisms in GSTT1, GSTZ1, and CYP2E1, disinfection by-products, and risk of bladder cancer in Spain. Environ Health Perspect. 2010;118(11): $1545-50$.

18. Larson JL, Bull RJ. Metabolism and lipoperoxidative activity of trichloroacetate and dichloroacetate in rats and mice. Toxicol Appl Pharmacol. 1992;115(2):268-77.

19. Ni YC, Wong TY, Lloyd RV, et al. Mouse liver microsomal metabolism of chloral hydrate, trichloroacetic acid, and trichloroethanol leading to induction of lipid peroxidation via a free radical mechanism. Drug Metab Dispos. 1996;24(1):81-90.

20. Pegram RA, Andersen ME, Warren SH, et al. Glutathione Stransferase-mediated mutagenicity of trihalomethanes in Salmonella typhimurium: contrasting results with bromodichloromethane off chloroform. Toxicol Appl Pharmacol. 1997;144(1):183-8.

21. Ross MK, Pegram RA. In vitro biotransformation and genotoxicity of the drinking water disinfection byproduct bromodichloromethane: DNA binding mediated by glutathione transferase theta 1-1. Toxicol Appl Pharmacol. 2004;195(2):166-81.

22. Ross MK, Pegram RA. Glutathione transferase theta 1-1-dependent metabolism of the water disinfection byproduct bromodichloromethane. Chem Res Toxicol. 2003;16(2):216-26.

23. Landi S, Hanley NM, Warren SH, et al. Induction of genetic damage in human lymphocytes and mutations in Salmonella by trihalomethanes: role of red blood cells and GSTT1-1 polymorphism. Mutagenesis. 1999;14(5):479-82.

24. Landi S, Naccarati A, Ross MK, et al. Induction of DNA strand breaks by trihalomethanes in primary human lung epithelial cells. Mutat Res. 2003;538(1-2):41-50.

25. Coffin JC, Ge R, Yang S, et al. Effect of trihalomethanes on cell proliferation and DNA methylation in female $\mathrm{B} 6 \mathrm{C} 3 \mathrm{~F} 1$ mouse liver. Toxicol Sci. 2000;58(2):243-52.

26. Tao L, Wang W, Li L, et al. Effect of dibromoacetic acid on DNA methylation, glycogen accumulation, and peroxisome proliferation in mouse and rat liver. Toxicol Sci. 2004;82(1):62-9. 
27. Ge R, Yang S, Kramer PM, et al. The effect of dichloroacetic acid and trichloroacetic acid on DNA methylation and cell proliferation in B6C3F1 mice. J Biochem Mol Toxicol. 2001;15(2):100-1006.

28. Pereira MA, Kramer PM, Conran PB, et al. Effect of chloroform on dichloroacetic acid and trichloroacetic acid-induced hypomethylation and expression of the c-myc gene and on their promotion of liver and kidney tumors in mice. Carcinogenesis. 2001;22(9):15119

29. Salas LA, Villanueva CM, Tajuddin SM, Amaral AFS, Fernandez AF, Moore LE et al. LINE1 methylation in granulocyte DNA and trihalomethane exposure is associated with bladder cancer risk. Epigenetics. 2014;9(11):1532-9.

30. Geter DR, Chang LW, Hanley NM, et al. Analysis of in vivo and in vitro DNA strand breaks from trihalomethane exposure. J Carcinog. 2004;3(1):2.

31. Geter DR, Moore TM, George MH, et al. Tribromomethane exposure and dietary folate deficiency in the formation of aberrant crypt foci in the colons of F344/N rats. Food Chem Toxicol. 2005;43(9): $1405-12$.

32. Jeong $\mathrm{CH}$, Wagner ED, Siebert VR, et al. Occurrence and toxicity of disinfection byproducts in european drinking waters in relation with the HIWATE epidemiology study. Environ Sci Technol. 2012;46(21):12120-8.

33. Stalter D, Dutt M, Escher BI. Headspace-free setup of in vitro bioassays for the evaluation of volatile disinfection by-products. Chem Res Toxicol. 2013;26(11):1605-14.

34. Salas LA, Cantor KP, Tardon A, et al. Biological and statistical approaches for modeling exposure to specific trihalomethanes and bladder cancer risk. Am J Epidemiol. 2013;178(4):652-60.

35. Villanueva CM, Castano-Vinyals G, Moreno V, et al. Concentrations and correlations of disinfection by-products in municipal drinking water from an exposure assessment perspective. Environ Res. 2012;114:1-11.

36. Ashley DL, Blount BC, Singer PC, et al. Changes in blood trihalomethane concentrations resulting from differences in water quality and water use activities. Arch Environ Occup Health. 2005;60(1): $7-15$.

37. Leavens TL, Blount BC, DeMarini DM, et al. Disposition of bromodichloromethane in humans following oral and dermal exposure. Toxicol Sci. 2007;99(2):432-45.

38. Lewis C, Suffet IH, Ritz B. Estimated effects of disinfection byproducts on birth weight in a population served by a single water utility. Am J Epidemiol. 2006;163(1):38-47.

39. Wright JM, Schwartz J, Dockery DW. Effect of trihalomethane exposure on fetal development. Occup Environ Med. 2003;60(3): 173-80.

40. Villanueva CM, Cantor KP, Cordier S, et al. Disinfection byproducts and bladder cancer. A pooled analysis. Epidemiology. 2004;15(3):357-67.

41. Font-Ribera L, Kogevinas M, Zock JP, et al. Short-term changes in respiratory biomarkers after swimming in a chlorinated pool. Environ Health Perspect. 2010;118(11):1538-44.

42. Riederer AM, Dhingra R, Blount BC, et al. Predictors of blood trihalomethane concentrations in NHANES 1999-2006. Environ Health Perspect. 2014;122(7):695-702.

43. Rivera-Nunez Z, Wright JM, Blount BC, et al. Comparison of trihalomethanes in tap water and blood: a case study in the United States. Environ Health Perspect. 2012;120(5):661-7.

44. Bader EL, Hrudey SE, Froese KL. Urinary excretion half-life of trichloroacetic acid as a biomarker of exposure to chlorinated drinking water disinfection by-products. Occup Environ Med. 2004;61(8):715-6.

45. Savitz DA. Invited commentary: biomarkers of exposure to drinking water disinfection by-products-are we ready yet? Am J Epidemiol. 2012;175(4):276-8.
46. Rook JJ. Formation of haloforms during chlorination of natural waters. Water Treat Exam. 1974;23(2):234- 43.

47. Chang SL. The safety of water disinfection. Annu Rev Public Health. 1982;3:393-418.

48. Crump KS, Guess HA. Drinking water and cancer: review of recent epidemiological findings and assessment of risks. Annu Rev Public Health. 1982;3:339-57.

49. King W. Epidemiological studies of disinfection by-products and cancer risk. In: Craun GF, Hauchman FS, Robinson DE, editors. Microbiological pathogens and disinfection by-products in drinking water: health effects and management of risks. Washington, DC: ILSI Press; 2001. p. 243-54.

50. Villanueva CM, Fernandez F, Malats N, et al. Meta-analysis of studies on individual consumption of chlorinated drinking water and bladder cancer. J Epidemiol Community Health. 2003;57(3): 166-73.

51. Costet N, Villanueva CM, Jaakkola JJ, et al. Water disinfection byproducts and bladder cancer: is there a European specificity? A pooled and meta-analysis of European case-control studies. Occup Environ Med. 2011;68(5):379-85. The most recent pooled analysis on bladder cancer and disinfection by-products.

52. IPCS. International Programme on chemical safety. Disinfectant and disinfectant by-products. Environmental Health Criteria 216. Geneva: United Nations Environment Programme (UNEP); International Labour Organization (ILO); World Health Organization (WHO), 2000.

53. Hrudey SE. Epidemiological inference and evidence on DBPs and human health. In: Hrudey SE, Charrois JW, editors. Disinfection by-products and human health. London: IWA Publishing; 2012. p. 213-82.

54. Bull R. Toxicological evaluation of experimental data that informs the magnitude of cancer risk from DBPs. In: Hrudey SE, Charrois JW, editors. Disinfection by-products and human health. London: IWA Publishing; 2012. p. 179-212.

55. Rahman MB, Driscoll T, Cowie C, et al. Disinfection by-products in drinking water and colorectal cancer: a meta-analysis. Int $\mathrm{J}$ Epidemiol. 2010;39(3):733-45.

56. IARC. Trichloroethylene and other chlorinated agents. IARC Monographs on the evaluation of carcinogenic risks to humans, vol. 106. Lyon, France: IARC Scientific publications; 2012.

57. Klinefelter GR, Suarez JD, Roberts NL, et al. Preliminary screening for the potential of drinking water disinfection byproducts to alter male reproduction. Reprod Toxicol. 1995;9(6):571-8.

58. Fenster L, Waller K, Windham G, et al. Trihalomethane levels in home tap water and semen quality. Epidemiology. 2003;14(6):650-8.

59. Luben TJ, Olshan AF, Herring AH, et al. The healthy men study: an evaluation of exposure to disinfection by-products in tap water and sperm quality. Environ Health Perspect. 2007;115(8):1169-76.

60. Xie SH, Li YF, Tan YF, et al. Urinary trichloroacetic acid levels and semen quality: a hospital-based cross-sectional study in Wuhan, China. Environ Res. 2011;111(2):295-300.

61. Iszatt $\mathrm{N}$, Nieuwenhuijsen MJ, Bennett $\mathrm{J}$, et al. Chlorination byproducts in tap water and semen quality in England and Wales. Occup Environ Med. 2013;70(11):754-60.

62. Zeng Q, Wang YX, Xie SH, et al. Drinking-water disinfection byproducts and semen quality: a cross-sectional study in China. Environ Health Perspect. 2014;122(7):741-6.

63. Windham GC, Waller K, Anderson M, et al. Chlorination byproducts in drinking water and menstrual cycle function. Environ Health Perspect. 2003;111(7):935-41.

64. MacLehose RF, Savitz DA, Herring AH, et al. Drinking water disinfection by-products and time to pregnancy. Epidemiology. 2008;19(3):451-8.

65. Waller K, Swan SH, DeLorenze G, et al. Trihalomethanes in drinking water and spontaneous abortion. Epidemiology. 1998;9(2):134-40. 
66. Savitz DA, Singer PC, Herring AH, et al. Exposure to drinking water disinfection by-products and pregnancy loss. Am J Epidemiol. 2006;164(11):1043-51.

67. Nieuwenhuijsen MJ, Grellier J, Iszatt N, Martinez D, Rahman MB, Villanueva CM. Literature review of meta-analyses and pooled analyses of disinfection by-products in drinking water and cancer and reproductive health outcomes. In: Halden RU, editor. Contaminants of emerging concern in the environment: ecological and human health considerations. Washington DC: American Chemical Society; 2010. p. 483-96.

68. Bove F, Shim Y, Zeitz P. Drinking water contaminants and adverse pregnancy outcomes: a review. Environ Health Perspect. 2002;110 Suppl 1:61-74.

69. Nieuwenhuijsen MJ, Toledano MB, Eaton N, et al. Chlorination disinfection byproducts in water and their association with adverse reproductive outcomes: a review. Occup Environ Med. 2000;57(2): 73-85.

70. Infante-Rivard C. Drinking water contaminants, gene polymorphisms, and fetal growth. Environ Health Perspect. 2004;112(11): 1213-6.

71. Hoffman CS, Mendola P, Savitz DA, et al. Drinking water disinfection by-product exposure and fetal growth. Epidemiology. 2008;19(5):729-37.

72. Villanueva CM, Gracia-Lavedan E, Ibarluzea J, et al. Exposure to trihalomethanes through different water uses and birth weight, small for gestational age, and preterm delivery in Spain. Environ Health Perspect. 2011;119(12):1824-30.

73. Levallois P, Gingras S, Marcoux S, et al. Maternal exposure to drinking-water chlorination by-products and small-for-gestationalage neonates. Epidemiology. 2012;23(2):267-76. One of the most recent studies on pregnancy outcomes and DBP exposure, based on a robust methodology and very detailed exposure assessment.

74. - Costet N, Garlantezec R, Monfort C, et al. Environmental and urinary markers of prenatal exposure to drinking water disinfection by-products, fetal growth, and duration of gestation in the PELAGIE birth cohort (Brittany, France, 2002-2006). Am J Epidemiol. 2012;175(4):263-75. The first study on pregnancy outcomes using a biomarker of DBP exposure (urinary trichloroacetic acid).

75. Grellier J, Benett J, Patelarou E, et al. Exposure to disinfection byproducts and adverse birth outcomes related to fetal growth and prematurity - a systematic review and meta-analysis. Epidemiology. 2010;21(3):300-13.

76. Zhou WS, Xu L, Xie SH, et al. Decreased birth weight in relation to maternal urinary trichloroacetic acid levels. Sci Total Environ. 2012;416:105-10.

77. Nieuwenhuijsen MJ, Martinez D, Grellier J, et al. Chlorination disinfection by-products in drinking water and congenital anomalies: review and meta-analyses. Environ Health Perspect. 2009;117(10):1486-93.

78. Agopian AJ, Waller DK, Lupo PJ, et al. A case-control study of maternal bathing habits and risk for birth defects in offspring. Environ Health. 2013;12:88.

79. Righi E, Bechtold P, Tortorici D, et al. Trihalomethanes, chlorite, chlorate in drinking water and risk of congenital anomalies: a population-based case-control study in Northern Italy. Environ Res. 2012;116:66-73.

80. Narotsky MG, Best DS, Rogers EH, et al. Integrated disinfection by-products mixtures research: assessment of developmental toxicity in Sprague-Dawley rats exposed to concentrates of water disinfected by chlorination and ozonation/postchlorination. J Toxicol Environ Health A. 2008;71(17):1216-21.
81. Walse SS, Mitch WA. Nitrosamine carcinogens also swim in chlorinated pools. Environ Sci Technol. 2008;42(4):1032-7.

82. Weaver WA, Li J, Wen Y, et al. Volatile disinfection by-product analysis from chlorinated indoor swimming pools. Water Res. 2009;43(13):3308-18.

83. Thickett KM, McCoach JS, Gerber JM, et al. Occupational asthma caused by chloramines in indoor swimming-pool air. Eur Respir J. 2002;19(5):827-32.

84. Villanueva CM, Font-Ribera L. Health impact of disinfection byproducts in swimming pools. Ann Ist Super Sanita. 2012;48(4): 387-96.

85. Goodman M, Hays S. Asthma and swimming: a meta-analysis. J Asthma. 2008;45(8):639-47.

86. Uyan ZS, Carraro S, Piacentini G, et al. Swimming pool, respiratory health, and childhood asthma: should we change our beliefs? Pediatr Pulmonol. 2009;44(1):31-7.

87. Bernard A, Carbonnelle S, Burbure C, et al. Chlorinated pool attendance, atopy and the risk of asthma during childhood. Environ Health Perspect. 2006;114(10):1567-73.

88. Bernard A, Carbonnelle S, Dumont X, et al. Infant swimming practice, pulmonary epithelium integrity, and the risk of allergic and respiratory diseases later in childhood. Pediatrics. 2007;119(6): 1095-103.

89. Bernard A, Nickmilder M, Voisin C, et al. Impact of chlorinated swimming pool attendance on the respiratory health of adolescents. Pediatrics. 2009;124(4):1110-8.

90. Bernard A, Nickmilder M, Voisin C. Outdoor swimming pools and the risks of asthma and allergies during adolescence. Eur Respir J. 2008;32(4):979-88.

91. Schoefer Y, Zutavern A, Brockow I, et al. Health risks of early swimming pool attendance. Int J Hyg Environ Health. 2008;211(34):367-73.

92. Font-Ribera L, Kogevinas M, Zock JP, et al. Swimming pool attendance and risk of asthma and allergic symptoms in children. Eur Respir J. 2009;34(6):1304-10.

93. Font-Ribera L, Villanueva CM, Gracia-Lavedan E, et al. Indoor swimming pool attendance and respiratory and dermal health in schoolchildren-HITEA Catalonia. Respir Med. 2014;108(7): 1056-9.

94. Font-Ribera L, Villanueva CM, Nieuwenhuijsen MJ, et al. Swimming pool attendance, asthma, allergies, and lung function in the Avon Longitudinal Study of Parents and Children cohort. Am J Respir Crit Care Med. 2011;183(5):582-8. The first study evaluating respiratory health in children and swimming pool attendance with a longitudinal design, data collected at different follow ups and the first including lung function measurements.

95. Jacobs JH, Fuertes E, Krop EJ, et al. Swimming pool attendance and respiratory symptoms and allergies among Dutch children. Occup Environ Med. 2012;69(11):823-30.

96. WHO. Guidelines for safe recreational water environments. Volume 2. Geneva: 2006. http://www.who.int/water_sanitation health/bathing/srwe2full.pdf.

97. BSHC. (Belgium Superior Health Council). The issue of chlorine in swimming pools: risk attendant on baby swimming and reflections on the different methods used to disinfect swimming pools. Brussels: 2012. http://health.belgium.be/internet2Prd/groups/ public/@public/@shc/documents/ie2divers/19076706.pdf.

98. Cantor KP, Hoover R, Mason TJ, et al. Associations of cancer mortality with halomethanes in drinking water. J Natl Cancer Inst. 1978;61(4):979-85.

99. Klinefelter GR, Strader LF, Suarez JD, et al. Continuous exposure to dibromoacetic acid delays pubertal development and compromises sperm quality in the rat. Toxicol Sci. 2004;81(2):419-29. 